\title{
'Climategate' scientist speaks out
}

\author{
Embattled climatologist Phil Jones faces his critics.
}

Phil Jones was director of the Climatic Research Unit (CRU) at the University of East Anglia in Norwich, UK, when, last November, more than 1,000 e-mails were illegally obtained from the university and posted on the Internet. Their contents sparked allegations of poor scientific practice at CRU, now the subject of an investigation that was launched on 11 February.

Yet until recently, Jones had remained almost silent on the affair, despite being vilified by critics and even receiving death threats. It's no wonder that in an interview with Nature last week, he spent much of his time with his arms crossed tightly in front of his chest, as if shielding himself from further attack.

One issue now under investigation is whether Jones or his CRU colleagues ever published data that they knew were potentially flawed, in order to bolster the evidence for man-made global warming. Under scrutiny is one of Jones's research papers (P. D. Jones et al. Nature 347, 169-172; 1990) on whether the apparent rise in temperature readings in the late twentieth century could be an artefact of measurement sites that shifted from the countryside to cities, which are warmer. The study concluded that this 'urban heat island' effect was negligible, and that the dominant effect was global climate change.

Jones and his co-authors used data from weather stations around the world; those in China "were selected on the basis of station history: we chose those with few, if any, changes in instrumentation, location or observation times", they wrote. But when this claim was questioned in 2007, it became clear that the raw data were obtained from a Chinese contact of one of Jones's co-authors, Wei-Chyung Wang of the University at Albany in New York, and details of the

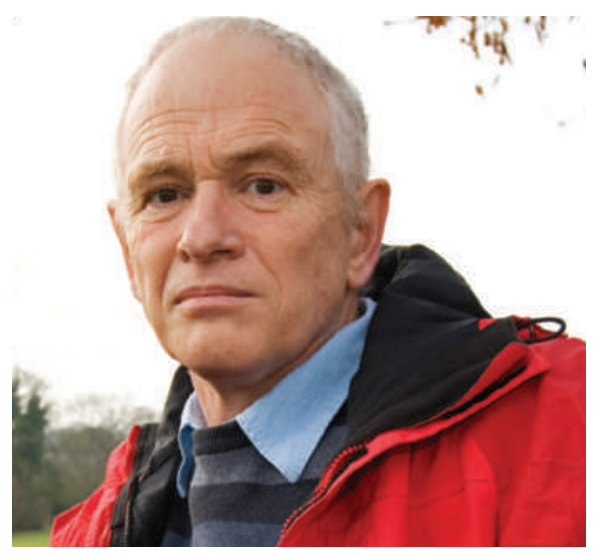

Phil Jones stands by his research.

stations' locations had subsequently been lost.

"I thought it was the right way to get the data," Jones says, but he now acknowledges that "the stations probably did move", and that not having a detailed history of stations' locations was sloppy. "It's not acceptable," he says. "[It's] not best practice." Despite this, Jones says that follow-up studies (P. D. Jones, D. H. Lister and Q. Li J. Geophys. Res. 113, D16122; 2008) verified the original conclusions for the Chinese data for the period 1954-83, showing that the precise location of weather stations was unimportant.

Jones says that he did not know that the stations' locations were questionable when they were included in the paper, but as its lead author he acknowledges his responsibility for ensuring the quality of the data. Asked if he will submit a correction to Nature, he replies: "I will give that some thought. It's worthy of consideration."

Jones rejects other allegations that he has selectively used data from tree rings - the thickness of which reflect annual temperatures and rainfall - to play down the importance of the Medieval Warm Period (MWP), a phase of natural warming that may have occurred 1,000 years ago. If the MWP was restricted to mild local warming, it would mean that present-day global warming is unprecedented for the past 1,000 years.

Scientists agree that the past 40 years of treering data are unreliable temperature proxies, and some argue that using them in older temperature reconstructions, as Jones has done, could understate past warm periods, including the MWP (see Nature 463, 284-287; 2010). "It potentially does," admits Jones, but he adds that analyses using other methods - proxy temperature markers from ice-core samples, for example - still show much the same temperature change over the past millennium.

Jones, an author on the most recent climate assessment report of the United Nations' Intergovernmental Panel on Climate Change (IPCC), also denies trying to censor dissenting voices but defends the right of IPCC authors to exclude papers if they are scientifically weak or irrelevant. "The IPCC [report] is an assessment, it's not a review," he says.

But he fears that this message, and the broader evidence for man-made climate change, is being lost in the aftermath of the 'climategate' affair as blogs and media reports dominate the debate. Jones is emphatic that climate researchers should speak out to defend their research. "[I'd] like to see the climate science community supporting the climate science more," he says. "Lots of them are trying but they're being drowned out." Olive Heffernan

See go.nature.com/RcDkAk for the full interview.

\section{Asian pollution delays inevitable warming}

The grey, sulphur-laden skies overlying parts of Asia have a bright side - they reflect sunlight back into space, moderating temperatures on the ground. Scientists are now exploring how and where pollution from power plants could offset, for a time, the greenhouse warming of the carbon dioxide they emit.

A new modelling study doubles as a thought experiment in how pollution controls and global warming could interact in China and India, which are projected to account for $80 \%$ of new coal-fired power in the coming years. If new power plants were to operate without controlling pollution such as sulphur dioxide $\left(\mathrm{SO}_{2}\right)$ and nitrogen oxides $\left(\mathrm{NO}_{x}\right)$, the study finds, the resulting haze would reflect enough sunlight to overpower the warming effect of
$\mathrm{CO}_{2}$ and exert local cooling.

But this effect would not be felt uniformly across the globe and would last only a few decades. In the long run, $\mathrm{CO}_{2}$ would always prevail, and the world could experience a rapid warming effect if the skies were cleaned up decades down the road.

"The paper highlights the fundamental inequity and iniquity of anthropogenic climate change: 'enjoy now and make others pay later'," says Meinrat Andreae, an aerosol expert at the Max Planck Institute for Chemistry in Mainz, Germany, who was not involved in the work. In fact, he says, dirty coal plants could be seen as "a very primitive form of geoengineering".

The study, which is under review at Atmospheric Chemistry and 